\title{
Editorial Expression of Concern: Sox9 Protects against Human Lung Fibroblast Cell Apoptosis Induced by LPS through Activation of the AKT/GSK3 $\beta$ Pathway
}

\author{
Z. Zhu' ${ }^{1}$, J. Dai ${ }^{1}$, Y. Liao ${ }^{1}$, and T. Wang ${ }^{2, a *}$ \\ ${ }^{1}$ Department of Clinical Laboratory, Ningbo No. 2 Hospital, 315010 Ningbo, Zhejiang, China \\ ${ }^{2}$ Department of Clinical Laboratory, First Affiliated Hospital of Xiamen University, 361003 Xiamen, Fujian, China \\ ${ }^{a} e$-mail: wangtao9596@126.com \\ Received September 9, 2016 \\ Revised October 25, 2016
}

DOI: $10.1134 / \mathrm{S} 0006297921100163$

The original article can be found online at https://doi.org/10.1134/S000629791705008X

The Editor-in-Chief is issuing an Editorial Expression of Concern for this article. The editorial team received a request from the corresponding author to retract the article due to being unable to reproduce the results. Unfortunately, the editorial team has been unable to obtain further information from the authors related to the specific issues with the article.

None of the authors have responded to any further correspondence from the editor. The authors' institution has not responded to a request for clarification. The Editor-in-Chief advises readers to interpret the results with caution. 